\title{
Eficácia de glifosato + haloxifope-p-metílico em associação com outros herbicidas no controle de capim-amargoso
}

\section{Efficacy of glyphosate + haloxyfop-p-methyl associated with other herbicides on the control of sourgrass}

\author{
José Junior NUNES ${ }^{1}$; Marco Antonio Moreira de FREITAS²; Tiago Pereira de SOUZA; \\ Wilton Lessa SILVA ${ }^{4}$; Paulo César Ribeiro da CUNHA ${ }^{5}$
}

${ }^{1}$ Autor para correspondência, Mestrando em Proteção de Plantas, Instituto Federal Goiano - Campus Urutaí, Rodovia Geraldo
Silva Nascimento, Km 2,5, Zona Rural | Urutaí - GO, CEP: 75.790-000 - Brasil, jose.junior@jlpesquisa.com.br.
${ }^{2}$ Doutor em Fitotecnia, IF Goiano - Campus Urutaí, marco.freitas@ifgoiano.edu.br.
${ }^{3}$ Mestre em Proteção de Plantas, IF Goiano - Campus Urutaí e pesquisador na MultCrop, tiago.souza@multcrop.com.
${ }^{4}$ Mestre em Proteção de Plantas, IF Goiano - Campus Urutaí e pesquisador na Solo \& Planta Consultoria Agronômica,
wilton.agro@yahoo.com.br.
${ }^{5}$ Doutor em Agronomia, IF Goiano - Campus Urutaí, paulo.cunha@ifgoiano.edu.br

Recebido em: 25-05-2020; Aceito em: 04-03-2021

\section{Resumo}

O uso de herbicidas inibidores da ACCase associados ao glifosato para o controle de capim-amargo é prática comum no Brasil. Entretanto quando se tem a necessidade da utilização de latifolicidas em uma mesma operação, interações negativas podem ocorrer. Logo o presente trabalho teve como objetivo avaliar quais latifolicidas potencialmente reduzem a eficácia da associação glifosato + haloxifope-p-metílico, e se a redução de eficácia inicial interfere no controle do capim-amargoso (Digitaria insularis) quando aplicações sequenciais são realizadas. Dois ensaios foram conduzidos em condições de campo com delineamento em blocos casualizados com quatro repetições. No primeiro, avaliou-se diferentes latifolicidas associados a mistura glifosato + haloxifope-p-metílico $\left(1440+120 \mathrm{~g} \mathrm{ha}^{-1}\right)$, enquanto no segundo, associou a mesma mistura ao 2,4-D (1005 g ha-1), seguida da aplicação de haloxifope-p-metílico $\left(120 \mathrm{~g} \mathrm{ha}^{-1}\right)$ ou paraquat $\left(300 \mathrm{~g} \mathrm{ha}^{-1}\right)$ dez dias após a primeira aplicação. Avaliações visuais de eficácia (0 a 100\%) foram realizadas aos 14, 21, 28 e 35 dias após a aplicação (DAA), e redução de biomassa fresca aos 35 DAA. Os herbicidas auxinicos 2,4-D e triclopir proporcionaram as maiores reduções no controle do capim-amargoso. Saflufenacil e imazetapir não apresentaram efeito negativo na eficácia de controle da associação glifosato + haloxifope-p-metílico. Quando 2,4-D foi associado a mistura padrão na primeira aplicação, a eficácia do paraquat em aplicação sequencial foi influenciada negativamente, porém, o mesmo efeito não foi observado para haloxifope-p-metílico, mostrando que no sistema de aplicações sequenciais, a adição de 2,4-D na primeira intervenção não comprometeu a segunda aplicação de graminicida.

Palavras-chave adicionais: Antagonismo; Digitaria insularis; graminicidas.

\begin{abstract}
The use of ACCase inhibitors mixed with glyphosate to control sourgrass is a common practice in Brazil. However, when there is a need for spraying a broadleaf herbicide during the same operation, negatives interactions may occur. Therefore, the present study aimed to assess potential broadleaf herbicides that can decrease the efficacy of the association glyphosate + haloxyfop-p-methyl; and if the initial reduction in efficacy can affect sourgrass control when sequential herbicides applications are performed. Two field trials were carried out with randomized complete block design and four replications. On the first one, different broadleaf herbicides were assessed when sprayed along with the combination glyphosate + haloxyfop-p-methyl $\left(1440+120 \mathrm{~g} \mathrm{ha}^{-1}\right)$; on the second one, 2,4-D (1005 $\mathrm{g} \mathrm{ha}^{-1}$ ) was added to the same combination followed by the application of either haloxyfop-p-methyl $\left(120 \mathrm{~g} \mathrm{ha}^{-1}\right)$ or paraquat $\left(300 \mathrm{~g} \mathrm{ha}^{-1}\right)$ ten days after. Control assessments were performed at $14,21,28$, and 35 days after application (DAA); and the fresh biomass reduction at 35 DAA. The synthetic auxins 2,4-D and triclopyr resulted in the worst performances when associated with the standard mix. On the other hand, saflufenacil and imazethapyr did not present any negative effect on sourgrass control by the combination glyphosate + haloxyfop-p-methyl. When 2,4-D was sprayed with the standard combination on the first application, paraquat efficacy was negatively affected, however, haloxyfop-p-methyl was not affected. Thus, demonstrating that in the system with sequential applications, adding 2,4-D on the first one, did not affect the second graminicide application.
\end{abstract}

Additional keywords: antagonismo; Digitaria insularis; graminicides. 


\section{Introdução}

Com o advento da tecnologia Roundup Ready, diversas mudanças ocorreram no sistema de manejo de plantas daninhas em nível mundial, dentre estas a seleção de espécies tolerantes ou resistentes ao herbicida glifosato tem ganhado papel importante no atual cenário de agrícola devido à dificuldade no controle destas plantas (Culpepper, 2006).

Dentre os casos de resistência já confirmados a glifosato no Brasil, o capim-amargoso (Digitaria insularis (L.) Mez ex Ekman) tem ganhado destaque devido a rápida dispersão e dificuldade no seu controle (Lopez-Ovejero et al., 2017, Heap, 2020). Além do glifosato, esta espécie já teve biótipos com resistência confirmada no Brasil aos herbicidas fenoxaprope-p-etílico e haloxifope-p-metílico ambos pertencentes ao grupo químico dos ariloxifenoxipropionatos (FOPs), inibidores da enzima ACCase (Heap, 2020).

O capim-amargoso é uma espécie herbácea, ereta, de colmos estriados e com 50 a $100 \mathrm{~cm}$ de altura, que forma touceiras a partir de curtos rizomas e tem como característica a elevada produção de sementes com alto poder germinativo (Lorenzi, 2014). Apresenta também alto poder competitivo, podendo reduzir drasticamente a produtividade de culturas de valor econômico (Gazziero et al., 2012). Segundo Gazziero et al. (2019), a capacidade de formação de rizomas em seu sistema caulinar eleva o potencial competitivo desta espécie, uma vez que plantas provenientes da rebrota de rizomas resultam em maiores perdas de produtividade na cultura da soja em relação as plantas provenientes de sementes, pois plantas rebrotadas já apresentam sistema radicular desenvolvido no momento da instalação da cultura, fato que favorece e acelera a competição, sendo mais um motivo para que o manejo desta planta daninha seja realizado em estágios iniciais de desenvolvimento (Gemelli et al., 2012).

Após o surgimento dos casos de resistência de capim-amargoso ao glifosato, a utilização dos herbicidas inibidores da enzima ACCase, pertencentes aos grupos químicos ariloxifenoxipropionatos (FOPs) e ciclohexanodionas (DIMs), principalmente em associações ao glifosato, passaram a ser uma das principais práticas adotadas para o controle desta espécie devido a resposta positiva observada (Melo et al., 2012). A utilização de produtos fitossanitários associados em mistura de tanque apresenta como uma de suas vantagens a redução no custo operacional, uma vez que duas operações são realizadas ao mesmo tempo (Gazziero, 2015). Entretanto em alguns casos, produtores enfrentam situações em que, além do capim-amargoso, há também a ocorrência de espécies de folha larga com baixa resposta ao glifosato na mesma área, como o caso das espécies de buva (Conyza spp.). Desta maneira, se tem a necessidade da utilização não só de herbicidas graminicidas em associação ao glifosato, mas também de latifolicidas.

No entanto, diversos trabalhos relatam que a mistura de latifolicidas e graminicidas apresenta antagonismo, com perda de eficácia no controle de gramí- neas, havendo a necessidade do aumento da dose do graminicida para compensar o efeito antagônico, ou então, a realização de duas operações separadas com intervalo entre elas (Trezzi et al., 2007, Leal et al., 2019). Em ambos os casos a vantagem operacional proporcionada pela mistura de tanque é colocada em xeque, havendo desta forma a necessidade de estudos prévios para determinação de práticas que visem minimizar possíveis impactos negativos. Embora a realização de duas operações seja uma opção para minimizar o impacto negativo do antagonismo, o capimamargoso em avançado estágio de desenvolvimento e com baixa resposta ao glifosato, necessita de pelo menos duas intervenções com produtos específicos para seu controle (Zobiole et al., 2016).

Diante da importância do capim-amargoso para as regiões agrícolas do Brasil, além da mistura de tanque e aplicações sequenciais serem amplamente utilizadas no país, o presente trabalho teve dois objetivos principais. O primeiro foi avaliar a eficácia da mistura glifosato + haloxifope-p-metílico associada a herbicidas de caráter latifolicida na eficácia de controle do capim-amargoso em pleno florescimento, visando encontrar uma potencial opção de latifolicida que não interfira no controle desta espécie. Já o segundo foi avaliar se a adição de 2,4-D a mistura glifosato + + haloxifope-p-metílico na primeira aplicação, apresenta redução na eficácia de controle do capim-amargoso no sistema de manejo com duas aplicações sequenciais.

\section{Material e métodos}

Os ensaios foram conduzidos sob condições de campo durante os meses de novembro/2019 a fevereiro/2020 em área agrícola comercial localizada nas coordenadas geográficas $15^{\circ} 35^{\prime} 04^{\prime \prime} \mathrm{S}$ e $54^{\circ} 20^{\prime \prime} 17^{\prime \prime} \mathrm{O}$, a 662 metros de altitude no município de Primavera do Leste - MT. Foram conduzidos dois experimentos no delineamento experimental de blocos ao acaso com quatro repetições, sendo cada unidade experimental composta por uma parcela de $3 \times 7 \mathrm{~m}$ altamente infestadas com plantas adultas e perenizadas de capim-amargoso em pleno florescimento. As aplicações foram realizadas com o auxílio de um pulverizador manual pressurizado a $\mathrm{CO}_{2}$, na pressão de trabalho de $2,5 \mathrm{kgf} \mathrm{cm}^{-2}$ e volume de calda de $150 \mathrm{~L} \mathrm{ha}^{-1}$. A barra de pulverização era constituída de seis pontas do tipo leque XR 110.02 e espaçadas $0,5 \mathrm{~m}$ entre si.

No primeiro experimento para avaliar o efeito da adição de diferentes herbicidas a mistura glifosato + + haloxifope-p-metílico em uma única aplicação, foram avaliadas seis combinações de herbicidas e a testemunha, de acordo com a Tabela 1. A aplicação foi realizada no dia 18 de novembro de 2019, no momento da aplicação a temperatura média do ar era de $27,4^{\circ} \mathrm{C}$, a umidade relativa era de $65 \%$, velocidade média do vento de $2,0 \mathrm{~km} \mathrm{~h}^{-1}$ com céu ensolarado sem a presença de nuvens. 
Tabela 1 - Descrição das combinações de herbicidas avaliadas no controle de capim-amargoso no primeiro ensaio. Herbicide treatments evaluated for sourgrass control in the first experiment.

\begin{tabular}{ccc}
\hline № & \multicolumn{1}{c}{ Tratamentos } & Dose (g de i.a./e.a. ha-1) \\
\hline 1 & Testemunha & - \\
2 & (1) Haloxifope-p-metílico + glifosato & $120+1440$ \\
3 & Haloxifope-p-metílico + glifosato + 2,4-D & $120+1440+1005$ \\
4 & Haloxifope-p-metílico + glifosato + triclopir & $120+1440+720$ \\
5 & Haloxifope-p-metílico + glifosato + imazetapir & $120+1440+100$ \\
6 & Haloxifope-p-metílico + glifosato + diurom & $120+1440+500$ \\
7 & Haloxifope-p-metílico + glifosato + saflufenacil & $120+1440+35$ \\
\hline
\end{tabular}

(1) adicionado óleo mineral na dose de $750 \mathrm{ml} \mathrm{ha}^{-1}$ nos tratamentos 2 ao 7.

Já no segundo experimento para avaliar se a adição de 2,4-D à mistura glifosato + haloxifope-p-metílico apresenta efeito negativo no sistema de manejo com duas aplicações sequenciais, utilizou-se a testemunha (não tratada) e seis tratamentos no esquema fatorial $2 \times 3$ (Tabela 2), sendo o primeiro fator a adição ou não do herbicida 2,4-D a associação glifosato + haloxifope-p-metílico, e o segundo fator a aplicação sequencial realizada aos 10 dias após a primeira aplicação (DAPA), sendo 1 - ausência de sequencial aos 10 DAPA; 2 - sequencial de haloxifope-p-metílico aos
10 DAPA e 3 - sequencial de paraquat aos 10 DAPA. A primeira aplicação foi realizada no dia 06 de janeiro de 2020, no momento da aplicação a temperatura média do ar era de $25,1^{\circ} \mathrm{C}$, a umidade relativa era de $70 \%$, velocidade média do vento de $1,3 \mathrm{~km} \mathrm{~h}^{-1}$ com céu ensolarado sem a presença de nuvens. Já a segunda aplicação foi realizada no dia 16 de janeiro de 2020, no momento da aplicação a temperatura média do ar era de $24,6{ }^{\circ} \mathrm{C}$, a umidade relativa era de $63 \%$, velocidade média do vento de $1,9 \mathrm{~km} \mathrm{~h}^{-1}$ com céu ensolarado sem a presença de nuvens.

Tabela 2 - Descrição dos tratamentos herbicidas aplicados na primeira e segunda aplicação no controle de capim-amargoso no segundo ensaio. Segunda aplicação realizada dez dias após a primeira. Herbicide treatments sprayed in the first and second application for sourgrass control in the second experiment. Second application performed ten days after the first.

\begin{tabular}{llllc}
\hline \multirow{2}{*}{ № } & \multicolumn{2}{c}{ 1a Aplicação } & \multicolumn{2}{c}{ 2a Aplicação (10 (1)DAPA) } \\
\cline { 2 - 5 } & \multicolumn{1}{c}{ Herbicidas } & Dose $(\mathrm{g} \mathrm{e.a.} \mathrm{ha-1})$ & Herbicidas & Dose (g e.a./i.a. ha-1) \\
\hline 1 & Testemunha & - & - & - \\
2 & (2) Haloxifope-p-metílico + glifosato $^{-1}$ & $120+1440$ & - & - \\
3 & Haloxifope-p-metílico + glifosato & $120+1440$ & Haloxifope & 120 \\
4 & Haloxifope-p-metílico + glifosato & $120+1440$ & Paraquat & 300 \\
5 & Haloxifope + glifosato + 2,4-D & $120+1440+1005$ & - & - \\
6 & Haloxifope + glifosato + 2,4-D & $120+1440+1005$ & Haloxifope & 120 \\
7 & Haloxifope + glifosato + 2,4-D & $120+1440+1005$ & Paraquat & 300 \\
\hline
\end{tabular}

(1) DAPA: dias após a primeira aplicação (A). (2) Adicionado óleo mineral na dose de $750 \mathrm{~mL} \mathrm{ha}^{-1}$ nos tratamentos 2 ao 7 nas duas aplicações.

No primeiro experimento as avaliações de eficácia de controle foram realizadas aos 14, 21, 28 e 35 dias após a aplicação (DAA), já no segundo foram realizadas nas mesmas datas, entretanto tomou-se como base a partir da segunda aplicação. Para tal, notas visuais foram atribuídas a cada unidade experimental, seguindo como base a escala de notas proposta pela Asociación Latinoamericana de Malezas de 0 a 100\%, em que $0 \%$ corresponde a ausência de sintomas e $100 \%$ morte total das plantas (Alam, 1974).

Aos 35 DAA também foi realizada a avaliação de biomassa fresca nos dois ensaios utilizando a metodologia descrita por Costa et al. (2014), com uso de um quadro metálico $(0,5 \times 0,5 \mathrm{~m})$ lançado de forma aleatória em cada parcela, coletando-se todo material vegetal de parte aérea proveniente das plantas de capim-amargoso, sendo realizada duas amostragens por unidade experimental para obtenção da média final de cada repetição. Logo após a coleta, o material coletado foi pesado no local para determinação da biomassa fresca em $\mathrm{g} \mathrm{m}^{-2}$, a qual foi utilizada para o cálculo de redução de biomassa fresca $(\mathrm{Rd})$ por meio da seguinte equação adaptada de Barroso et al. (2014):

$\mathrm{Rd}=100-\frac{\text { Biomassa fresca da planta tratada }}{\text { Biomassa fresca da testemunha }} \times 100$ 
Em que: a biomassa fresca da testemunha (g) foi a média de massa fresca na ausência da aplicação de herbicidas; a biomassa fresca da planta tratada (g) foi a média de massa fresca obtida após a aplicação de cada respectivo tratamento.

Todos os dados foram submetidos a análise de variância pelo teste $\mathrm{F}(\mathrm{p}<0,05)$, e quando significativo, as médias foram comparadas pelo teste de Scott-Knott $(p<0,05)$ por meio do Software $R$ (R Core Team, 2018).

\section{Resultados e discussão}

De modo geral, no primeiro experimento não foram constatados altos índices de controle, sendo que apenas aos 28 DAA os tratamentos glifosato + haloxifope-p-metílico, glifosato + haloxifope-p-metílico + imazetapir e glifosato + haloxifope-p-metílico + saflufenacil proporcionaram eficácia superior a $80 \%$ (Tabela 3). A baixa resposta de controle está possivelmente correlacionada ao estágio das plantas no momento da aplicação, as quais estavam em pleno florescimento, com touceiras bem formadas.

A maior dificuldade de controlar o capim-amargoso em avançado estágio de desenvolvimento reside no fato de que plantas provenientes de rizomas podem apresentar maior espessura na epiderme das faces adaxial e abaxial e também maior espessura da lâmina foliar, quando comparadas a plantas provenientes de sementes. Além disso, também apresentam grande quantidade de amido nos rizomas, que pode afetar a translocação dos herbicidas utilizados e permitir a rebrota da parte aérea das plantas tratadas (Machado et al., 2008). Segundo Andrade et al. (2019), para cada 10 unidades na escala de codificação de estádio fenológico, $\mathrm{BBCH}$, que a planta de capim-amargoso avançou em seu desenvolvimento, necessitou-se de um incremento de $150 \mathrm{~g} \mathrm{ha}^{-1}$ de glifosato para se obter o mesmo controle. Em situações como esta, a boa eficácia é dependente de aplicações sequenciais para o bom controle desta espécie (Zobiole et al., 2016). O que não ocorreu no primeiro experimento, uma vez que todos os tratamentos foram aplicados uma única vez.

Ao comparar a associação glifosato + haloxifope-p-metílico aplicada de forma isolada e em mistura aos demais herbicidas avaliados, foi possível observar que 2,4-D e triclopir foram os que resultaram nas maiores reduções de eficácia no controle do capim-amargoso em todas as avaliações realizadas, sendo os maiores níveis de redução observados na última avaliação aos 35 DAA, com 45,8 e 36,3\% de redução por parte do 2,4-D e triclopir, respectivamente (Tabela 3).

O antagonismo causado pela adição de 2,4-D a associação glifosato + haloxifope-p-metílico também foi constatado por Pereira et al. (2018), que observaram até $50 \%$ de redução no controle de capim-amargoso pela adição de 2,4-D ou dicamba, entretanto, não observaram antagonismo por parte do halauxifen-metil, mostrando desta forma, existir alternativas de herbicidas mimetizadores de auxina que possam ser utilizados com graminicidas sem ter efeito antagônico.
Alguns fatores tendem a afetar a ocorrência ou não do antagonismo entre graminicidas e latifolicidas, como por exemplo, a proporção de dose de cada produto utilizado e o intervalo entre as aplicações, quando estas ocorrem de maneira isolada para cada classe de produto (Trezzi et al., 2007, Leal et al., 2019). Osipe (2015), observou antagonismo da mistura cletodim $\left(168 \mathrm{~g} \mathrm{ha}^{-1}\right)+2,4-\mathrm{D}$ apenas pela maior dose do latifolicida, a qual foi de $670 \mathrm{~g} \mathrm{ha}^{-1}$, ao passo que $402 \mathrm{~g} \mathrm{ha}^{-1}$ não resultou em antagonismo. Na mesma ocasião Osipe (2015) também observou que o tamanho das plantas de capim-amargoso no momento da aplicação teve influência na ocorrência do antagonismo, uma vez que, em plantas tratadas em pleno florescimento com cerca de $70 \mathrm{~cm}$ de altura, não se observou antagonismo por parte de nenhuma das doses avaliadas de 2,4-D, já quando as plantas foram tratadas também em pleno florescimento, entretanto, com cerca de $120 \mathrm{~cm}$ de altura todas as doses de 2,4-D foram antagônicas.

Ao contrário do que foi observado com 2,4-D e triclopir, quando glifosato + haloxifope-p-metílico foram aplicados em associação a imazetapir ou saflufenacil não houve redução de eficácia por parte das combinações (Tabela 3). O mesmo foi relatado por Procópio et al. (2006a), que não observaram antagonismo pela associação de imazetapir (100 $\left.\mathrm{g} \mathrm{ha}^{-1}\right)$ ou clorimuron etílico $\left(10 \mathrm{~g} \mathrm{ha}^{-1}\right)$ ao glifosato $\left(1620 \mathrm{~g} \mathrm{ha}^{-1}\right)$ no controle do capim-amargoso.

Em relação ao saflufenacil, Dalazen et al. (2015) observaram efeito sinérgico por parte de sua associação ao glifosato no controle de buva (Conyza bonariensis (L.) Cronquist). Os autores inferem que a ação do saflufenacil é mais lenta quando comparada a outros herbicidas do mesmo mecanismo de ação, e que suas características físico-químicas permitem sua movimentação na planta, possibilitando que o glifosato seja absorvido antes da ação de contato e destruição dos tecidos de absorção. Fato confirmado por Eubank et al. (2013), que não observaram redução na absorção de glifosato por Conyza canadensis (L.) Cronquist pela adição de saflufenacil. Já Grossmann et al. (2011), verificaram movimentação do saflufenacil em Solanum nigrum L. e Ipomoea purpurea (L.) Roth, uma vez que após tratada apenas uma das folhas de cada espécie, foi suficiente para observar a morte total das plantas 14 dias após o tratamento, ao contrário do observado por parte do flumioxazim, que nas mesmas condições provocou apenas necrose na folha tratada, e as plantas continuaram a se desenvolver normalmente. Os autores atribuem a movimentação do saflufenacil as suas características físico-químicas e sua ação mais lenta na inibição da enzima Protox.

Aos 14 e 21 DAA o tratamento com diurom associado a glifosato + haloxifope-p-metílico apresentou média de controle superior a mistura isolada. Neste tratamento foi possível notar o efeito dessecante por parte de diurom nas plantas de capim-amargoso, fato já relatado em outras espécies (Steele et al., 2008). Entretanto sua eficácia não foi duradoura, sendo que a partir 
dos 28 DAA, médias de controle significativamente inferiores foram observadas (Tabela 3).

Segundo Steele et al. (2008), a aplicação de diurom junto ao glifosato não interferiu no controle e na redução de massa em Ipomoea cordatotriloba Dennst. Entretanto, foi observado que a adição de diurom afetou negativamente a translocação do glifosato para o sistema radicular das plantas. Logo infere-se que essa possível redução na translocação do glifosato possa ser o motivo pelo qual a adição de diurom a associação glifosato + haloxifope-p-metílico apresentou eficácia inferior a mistura isolada. Uma vez que, o capim-amargoso produz rizomas em seu sistema radicular, e para se ter eficácia de controle satisfatória é preciso que os herbicidas sejam translocados até essas estruturas. Quando o tratamento não é eficaz, ocorre o rebrote das plantas e queda na eficácia de controle (Correia \& Durigan, 2009).
Em relação a redução de biomassa fresca, a análise estatística possibilitou separar os tratamentos em dois grupos. No primeiro deles pode-se citar os tratamentos que não afetaram a redução de biomassa fresca, sendo imazetapir, diurom e saflufenacil. Estes herbicidas quando associados a glifosato + haloxifopep-metílico apresentaram médias de redução de biomassa similares ao da mistura isolada. Já no segundo grupo, os tratamentos que afetaram negativamente a redução de biomassa fresca foram o 2,4-D e triclopir. Quando associados a glifosato + haloxifope-p-metílico resultaram em redução de biomassa significativamente inferior ao da mistura isolada, sendo apenas 3,8 e $11,5 \%$ para $2,4-\mathrm{D}$ e triclopir, respectivamente, ao passo que a mistura isolada reduziu $40,8 \%$ o peso médio de biomassa fresca em relação a testemunha não tratada (Tabela 3).

Tabela 3 - Eficácia de controle do capim-amargoso observada ao longo das avaliações realizadas e porcentagem de redução de biomassa fresca em relação a testemunha não tratada aos 35 DAA. Dados do primeiro experimento. Sourgrass control efficacy over assessments and the percentage of fresh biomass reduction in function of the untreated control at 35 days after application $(D A A)$. Data from the first experiment.

\begin{tabular}{|c|c|c|c|c|c|c|}
\hline \multirow{2}{*}{\multicolumn{2}{|c|}{ Tratamentos }} & \multicolumn{4}{|c|}{ Controle (\%) } & \multirow{2}{*}{$\begin{array}{l}\text { Redução de biomassa } \\
\text { fresca (\%) }\end{array}$} \\
\hline & & (1) $14 \mathrm{DAA}$ & $21 \mathrm{DAA}$ & $28 \mathrm{DAA}$ & 35 DAA & \\
\hline 1 & Testemunha & $0,0-$ & 0,0 & 0,0 & 0,0 & 0,0 \\
\hline 2 & Glifosato + haloxifope & $60,5^{(2)} \mathrm{b}$ & $70,5 \mathrm{~b}$ & 81,3 a & $71,3 \mathrm{~b}$ & $40,8 \mathrm{a}$ \\
\hline 3 & Glifosato + haloxifope + 2,4-D & $55,5 \mathrm{c}$ & $52,5 \mathrm{e}$ & $45,0 \mathrm{c}$ & 25,5 e & $3,8 \mathrm{~b}$ \\
\hline 4 & Glifosato + haloxifope + triclopir & $55,5 \mathrm{c}$ & 62,3 & $66,3 \mathrm{~b}$ & $35,0 \mathrm{~d}$ & $11,5 b$ \\
\hline 5 & Glifosato + haloxifope + imazetapir & $53,8 \mathrm{c}$ & 66,3 & 80,0 a & 78,5 a & $38,1 \mathrm{a}$ \\
\hline 6 & Glifosato + haloxifope + diurom & 67,3 a & 76,3 & $70,8 \quad b$ & $62,5 \mathrm{c}$ & $35,4 \mathrm{a}$ \\
\hline 7 & Glifosato + haloxifope + saflufenacil & $63,0 \mathrm{~b}$ & 77,5 & 81,8 a & 75,8 a & $43,5 \mathrm{a}$ \\
\hline & C.V. (\%) & 3,05 & 3,56 & 5,02 & 4,54 & 21,53 \\
\hline
\end{tabular}

(1)Dias após a aplicação. (2) Médias seguidas da mesma letra na coluna não diferem estatisticamente entre si através do teste de Scott-Knott a $5 \%$ de probabilidade.

Diferente do primeiro ensaio, no segundo experimento onde para alguns tratamentos foram realizadas duas aplicações de herbicidas de forma sequencial (Tabela 2), maiores médias de eficácia foram observadas mesmo com capim-amargoso em pleno florescimento, mostrando ${ }_{2}$ desta forma ${ }_{2}$ que plantas em avançado estágio de desenvolvimento necessitam de intervenções sequenciais para a boa eficácia de controle, corroborando com Zobiole et al. (2016) (Tabela 4). Um fato em comum entre os dois experimentos, foi que, principalmente aqueles tratamentos menos efetivos, a eficácia foi reduzindo ao longo do tempo decorrido da aplicação devido ao rebrote das plantas, fato também observado por Correia \& Durigan (2009).

Apesar de novamente ter sido observada redução de eficácia quando 2,4-D foi adicionado a mistura glifosato + haloxifope-p-metílico, a redução inicial não interferiu na eficácia da segunda aplicação de haloxifope-p-metílico realizada aos dez dias após a primeira, uma vez que apenas aos 35 DAA foi possível observar diferença significativa entre os tratamentos 3 (glifosato + haloxifope-p-metílico e sequencial de haloxifope-pmetílico) e 6 (glifosato + haloxifope-p-metílico + 2,4-D e sequencial de haloxifope-p-metílico), e mesmo com a pequena diferença o tratamento 6 se manteve com eficácia superior a $80 \%$ de controle. Já nas demais avaliações e na redução de biomassa fresca, os dois tratamentos foram semelhantes entre si (Tabela 4).

Segundo Leal et al. (2019), quando o 2,4-D foi aplicado após haloxifope-p-metílico em um intervalo mínimo de seis dias entre as aplicações, não se observou efeito antagônico por parte do latifolicida no controle de capim-amargoso no estágio de três a quatro perfiIhos. Já quando o 2,4-D foi aplicado associado ao haloxifope-p-metílico ou em um intervalo de três dias ocorreu redução de eficácia. Os autores relatam que o antagonismo possivelmente ocorreu devido a capacidade das plantas tratadas com 2,4-D em metabolizar o graminicida em compostos menos tóxicos. 
A capacidade da planta em metabolizar o herbicida foi observada por Han et al. (2013), na ocasião os autores não observaram efeito do pré-tratamento das plantas de azevém (Lolium rigidum Gaudin) com 2,4-D na absorção ou movimentação do diclofopmethyl, entretanto observaram que a metabolização do graminicida a compostos não tóxicos aconteceu de forma mais rápida. Fato similar ao mecanismo de resistência desenvolvido por biótipos de azevém aos herbicidas inibidores da ACCase.

Quando a segunda aplicação foi realizada com paraquat, houve diferença significativa pela adição de 2,4-D na primeira aplicação. Uma vez que, apesar de até os 21 DAA os tratamentos 4 (glifosato + haloxifopep-metílico e sequencial de paraquat) e 7 (glifosato + haloxifope-p-metílico + 2,4-D e sequencial de paraquat) terem proporcionado controle semelhante, aos 28 e 35 DAA o tratamento 7 foi significativamente inferior ao seu comparativo. A melhor eficácia de paraquat nas duas primeiras avaliações, está ligada a ação rápida de contato deste herbicida, entretanto, por ser uma planta perene em estágio avançado de desenvolvimento, rebrotes ocorreram. Apesar da diferença significativa em eficácia, os dois tratamentos resultaram em médias de redução de biomassa fresca similares entre si (Tabela 4).

Tabela 4 - Eficácia de controle do capim-amargoso observada ao longo das avaliações realizadas e porcentagem de redução de biomassa fresca em relação a testemunha não tratada aos 35 dias após a aplicação (DAA). Dados do segundo experimento. Sourgrass control efficacy observed throughout the evaluations carried out and the percentage of fresh biomass reduction in relation to the untreated control at 35 days after application (DAA). Data from the second experiment.

\begin{tabular}{|c|c|c|c|c|c|c|c|}
\hline & \multirow{2}{*}{\multicolumn{2}{|c|}{ Tratamento }} & \multicolumn{4}{|c|}{ Controle (\%) } & \multirow{2}{*}{$\begin{array}{c}\text { Redução de biomassa } \\
\text { fresca (\%) }\end{array}$} \\
\hline & & & $14^{\text {(1) DAA }}$ & 21DAA & 28DAA & 35DAA & \\
\hline 1 & Testemunha & & $0,0-$ & $0,0-$ & $0,0-$ & $0,0-$ & $0,0-$ \\
\hline 2 & Glifosato + Haloxifope & - & $55,0^{(2) b}$ & $61,3 \mathrm{~b}$ & $70,0 \mathrm{c}$ & $66,3 d$ & $48,2 \mathrm{~b}$ \\
\hline 3 & Glifosato + Haloxifope & Haloxifope & $54,3 \mathrm{~b}$ & $63,0 \mathrm{~b}$ & $89,5 \mathrm{a}$ & $92,5 \mathrm{a}$ & $64,5 \mathrm{a}$ \\
\hline 4 & Glifosato + Haloxifope & Paraquat & 84,3 a & $83,0 \mathrm{a}$ & $76,0 \mathrm{~b}$ & $76,5 \mathrm{c}$ & $44,5 \mathrm{~b}$ \\
\hline 5 & Glif. + Halox.+ 2,4-D & - & $50,0 \mathrm{~b}$ & $51,3 \mathrm{c}$ & $50,0 \mathrm{e}$ & 40,3 e & $29,8 \mathrm{c}$ \\
\hline 6 & Glif. + Halox.+ 2,4-D & Haloxifope & $50,0 \mathrm{~b}$ & $61,5 b$ & 87,3 a & $82,5 \mathrm{~b}$ & 55,8 a \\
\hline 7 & Glif. + Halox.+ 2,4-D & Paraquat & $83,3 \mathrm{a}$ & $80,8 \mathrm{a}$ & $54,3 d$ & $44,0 \mathrm{e}$ & $42,1 \mathrm{~b}$ \\
\hline & C.V. (\%) & & 6,73 & 3,69 & 2,82 & 5,92 & 15,55 \\
\hline
\end{tabular}

(1) Dias após a aplicação. (2) Médias seguidas da mesma letra na coluna não diferem estatisticamente entre si através do teste de Scott-Knott ao nível de 5\% de probabilidade.

Ao se traçar um comparativo entre haloxifopep-metílico e paraquat como opções de dessecação sequencial para o controle de capim-amargoso, constatou-se que em ambas as situações haloxifope-p-metílico se sobressaiu com a melhor eficácia. Mostrando desta forma que o manejo de capim-amargoso em estágio avançado de desenvolvimento, é dependente de aplicações sequenciais, e que fatores que afetam negativamente a primeira aplicação, como por exemplo a adição de 2,4-D, tendem a prejudicar mais o produto com caráter de contato, devido ao hábito perene do capim-amargoso e sua capacidade de rebrotar a partir de seus rizomas (Procópio et al., 2006b).

\section{Conclusões}

Diante dos dados apresentados, os herbicidas auxinicos 2,4-D e triclopir quando associados a glifosato + haloxifope-p-metílico reduziram significativamente o controle do capim-amargoso, enquanto imazetapir e saflufenacil não afetaram a eficácia de glifosato + + haloxifope-p-metílico. Podendo ser opções para futuros estudos visando avaliar o controle tanto de plantas gramíneas quanto eudicotiledoneas em uma mesma operação.

Já no sistema de aplicações sequenciais, observou-se que o controle do capim-amargoso em pleno florescimento é dependente desta modalidade de manejo. Quando o 2,4-D foi adicionado na primeira intervenção, não houve redução na eficácia de haloxifope-p-metílico na segunda aplicação, possivelmente dado ao intervalo entre as duas intervenções. Entretanto quando a segunda intervenção foi realizada com paraquat, foi observada redução significativa na eficácia deste tratamento pela aplicação do 2,4-D na primeira intervenção.

\section{Referências}

Andrade J, Presoto J, Carvalho S (2019) Interferência do estádio fenológico do capim-amargoso sobre a eficácia do herbicida glyphosate. Revista Brasileira de Herbicidas 18(3):1-7. doi: 10.7824/rbh.v18i3.671.

Asociación Latinoamericana de Malezas - ALAM (1974) Recomendaciones sobre unificación de los sistemas de evaluación en ensayos de control de malezas. ALAM 1(1):35-38.

Barroso AAM, Albrecht AJP, Reis FC, Filho RV (2014) Interação entre herbicidas inibidores da ACCase e diferentes formulações de glyphosate no controle de capimamargoso. Planta Daninha 32(3):619-627. doi: $10.1590 /$ S0100-83582014000300018. 
Correia NM, Durigan JC (2009) Manejo químico de plantas adultas de Digitaria insularis com glyphosate isolado e em mistura com chlorimuron-ethyl ou quizalofop-p-tefuril em área de plantio direto. Bragantia 68(3):689-697. doi:

10.1590/S0006-

87052009000300016 .

Costa NV, Andrade DC, Dourado RF, Pavan GC, Costa ACPR (2014) Dessecação da Brachiaria ruziziensis com paraquat antes da semeadura da soja. Revista Brasileira de Herbicidas 13(3):235-244. doi: 10.7824/rbh.v13i3.277.

Culpepper AS (2006) Glyphosate-induced weed shifts. Weed Technology 20(2):277-281. doi: 10.1614/WT-04155R.1.

Dalazen G, Kruse ND, Machado SLO, Balbinot A (2015) Sinergismo na combinação de glifosato e saflufenacil para o controle de buva. Pesquisa Agropecuária Tropical 45(2):249-256. doi: 10.1590/1983$40632015 \mathrm{v} 4533708$.

Eubank TW, Nandula VK, Reddy KN, Poston DH, Shaw DR (2013) Saflufenacil efficacy on horseweed and its interaction with glyphosate. Weed Biology and Management 13(4):135-143. doi: 10.1111/wbm.12022.

Gazziero DLP, Adegas FS, Silva AF, Concenço G (2019) Estimating yield losses in soybean due to sourgrass interference. Planta Daninha 37. doi: 10.1590/s0100-83582019370100047.

Gazziero DLP (2015) Misturas de agrotóxicos em tanque nas propriedades agrícolas do Brasil. Planta Daninha 33(1):83-92. doi: 10.1590/S010083582015000100010 .

Gazziero DLP, Voll E, Fornarolli D, Vargas L, Adegas FS (2012) Efeitos da convivência do capim-amargoso na produtividade da soja. In: Congresso Brasileiro da Ciência das Plantas Daninhas, 28, Anais... Campo Grande: Sociedade Brasileira da Ciência das Plantas Daninhas 345-350.

Gemelli A, Oliveira Junior RS, Constantin J, Braga G, Braz P, Jumes TMC, Neto AMO, Dan HA, Biffe DF (2012) Aspectos da biologia de Digitaria insularis resistente ao glyphosate e implicações para o seu controle. Revista Brasileira de Herbicidas 11(2):231-240. doi: 10.7824/rbh.v11i2.186.

Grossmann K, Hutzler J, Caspar G, Kwiatkowski J, Brommer CL (2011) Saflufenacil (KixorTM): biokinetic properties and mechanism of selectivity of a new protoporphyrinogen IX oxidase inhibiting herbicide. Weed Science 59(3):290-298. doi: 10.1614/WS-D-1000179.1.
Han H, Yu Q, Cawthray GR, Powles SB (2013) Enhanced herbicide metabolism induced by 2,4-D in herbicide susceptible Lolium rigidum provides protection against diclofop-methyl. Pest Manag Sci 69(9):9961000. doi: $10.1002 /$ ps.3552.

Heap I (2020) International survey of herbicide-resistant weeds. Disponível em: <http://www.weedscience.org/> (Acesso em 30 fev 2020).

Leal JFL, Souza AS, Ribeiro SRS, Oliveira GFPB, Araujo ALS, Borella J, Langaro AC, Machado AFL, Pinho CF (2019) 2,4-Dichlorophenoxyacetic-N-methylmethanamine and haloxyfop-P-methyl interaction: Sequential and interval applications to effectively control sourgrass and fleabane. Agronomy Journal 112(2):1216-1226. doi: 10.1002/agj2.20018.

Lopez Ovejero R, Takano HK, Nicolai M, Ferreira A, Melo MSC, Cavenaghi AL, Christoffoleti PJ, Oliveira RS (2017) Frequency and dispersal of glyphosate resistant sourgrass (Digitaria insularis) populations across Brazilian agricultural production areas. Weed Science 65(2):285-294. doi: 10.1017/wsc.2016.31.

Lorenzi H (2014) Manual de identificação e controle de plantas daninhas: plantio direto e convencional. Nova Odessa: Instituto Plantarum. 384p.

Machado AFL, Meira RMS, Ferreira LR, Ferreira FA, Tuffi Santos LD, Fialho CMT, Machado MS (2008) Caracterização anatômica de folha, colmo e rizoma de Digitaria insularis. Planta Daninha 26(1):1-8. doi: 10.1590/S0100-83582008000100001.

Melo MSC, Rosa LE, Brunharo CACG, Nicolai M, Christoffoleti PJ (2012) Alternativas para o controle químico de capim-amargoso (Digitaria insularis) resistente ao glyphosate. Revista Brasileira de Herbicidas 11(2):195-203. doi: 10.7824/rbh.v11i2.145.

Osipe JB (2015) Espectro de controle, comportamento em misturas e intervalo de segurança para a semeadura de soja e algodão para os herbicidas dicamba e 2,4-D. UEM (Tese de doutorado em Agronomia).

Pereira GR, Zobiole LHS, Rossi CVS (2018) Resposta no controle de capim-amargoso a mistura de tanque de glyphosate e haloxifope com auxinas sintéticas. Revista Brasileira de Herbicidas 17(2):1-7. doi: 10.7824/rbh.v17i2.606.

Procópio SO, Menezes CCE, Pires FR, Barroso ALL, Cargnelutti Filho A, Rudovalho MC, Moraes RV, Silva MVV, Caetano JO (2006a) Eficácia de imazethapyr e chloriuron-ethyl em aplicações de pré-semeadura da cultura da soja. Planta Daninha 24(3):467-473. doi: 10.1590/S0100-83582006000300007. 
Procópio SO, Pires FR, Menezes CCE, Barroso ALL, Moraes RV, Silva MVV, Queiroz RG, Carmo ML (2006b) Efeitos de dessecantes no controle de plantas daninhas na cultura da soja. Planta Daninha 24(1):193197. doi: 10.1590/S0100-83582006000100024.

R Core Team (2018) R: A language and environment for statistical computing. R Foundation for Statistical Computing, Vienna, Austria. URL https://www.R-project.org/.

Steele GL, Senseman SA, Sciumbato AS, Chandler LM (2008) Diuron reduces absorption and translocation of glyphosate in sharppod morningglory (Ipomoea cordatotriloba). Weed Technology 22(3):414-419. doi: 10.1614/WT-07-159.1
Trezzi MM, Matei D, Vidal RA, Kruse ND, Gustmam MS, Viola R, Machado A, Silva HL (2007) Antagonismo das associações de clodinafop-propargyl com metsulfuronmethyl e 2,4-D no controle de azevém (Lolium multiflorum). Planta Daninha 25(4):839-847. doi: $10.1590 /$ S0100-83582007000400021.

Zobiole LHS, Krenchinski FH, Albrecht AJP, Pereira G, Lucio FR, Rossi C, Rubin RS (2016) Controle de capimamargoso perenizado em pleno florescimento. Revista Brasileira de Herbicidas 15(2):157-164. doi: 10.7824/rbh.v15i2.474. 